\title{
O ECAD (Escritório Central de Arrecadação e Distribuição) ${ }^{(*)}$
}

\author{
Antônio Chaves \\ Catedrático de Direito Civil da Faculdade de \\ Direito da Universidade de São Paulo \\ Vice-Presidente do Conselho Nacional do Direito \\ de Autor (CNDA) \\ Presidente do Instituto Interamericano do Direitu \\ de Autor (IIDA)
}

SUMARIO: 1. Organização do ECAD - 2. Estatutos e Regimento - 3.

Criticas e sua refutasâo - 4. O ECAD mudou no pamorama da cobransa do direito de autor no Brasil - 5. As denuncias e a "intervencão" - 6 . Auditoria nas Associasões.

\section{Organização do ECAD}

A Lei $n^{0} 5.988$ de 13/12/1974, determinou que as associações de titulares de direitos do autor e dos que lhes são conexos, se integrassem, no prazo de 120 dias a partir da data da instalação do Conselho Nacional de Direito Autoral (art. 133) num Escritório Central de Arrecadação e Distribuição (ECAD).

Determinou por sua vez 0 art. 11 do Decreto $\mathrm{n}^{\circ} 76.275$, de 15/09/1975, que organizou o Conselho Nacional de Direito Autoral, que, uma vez instalado, elaborasse o Conselho o seu regimento interno, "bem como as normas relativas à constituição, funcionamento e fiscalização do Escritório Central de Arrecadação e Distribuição".

Para compor o Conselho Nacional de Direito Autoral (CNDA), "órgão de fiscalização, consulta e assistência", criado pela mesma lei foram nomeados nos termos do Decreto no 84.252, de 28/11/1979, sem qualquer critério demagógico ou paternalista, pela primeira vez na história do País, pessoas realmente versadas na matéria: um representante do MEC; um representante do MT; um representante do MRE; sete especialistas, dos quais três escolhidos mediante indicação,

* Contribuição oferecida para a reunião do Conselho Panamericano da Confederação Internacional de Autores e Compositores, de 20-10-1981, em Buenos Aires, para a qual foi convidado a título de observador. 
em listas tríplices, pelas associações de titulares de direito autorais, e três Conselheiros Suplentes, um dos quais pelo mesmo critério.

Órgão até então quase que inoperante, o CNDA, em sessão plenária do dia 14/05/1980 baixou a Resolução n" 19, que, "altera e consolida normas relativas a organização, funcionamento e fiscalização do Escritório Central de Arrecadação e Distribuição".

Pelo art. $2^{\circ}$ cabe ao mesmo "autorizar a utilização de obras intelectuais, tanto em relação a direitos de autor como aos que lhes são conexos delas decorrentes, arrecadar e distribuir as retribuições oriundas dessas utilizações".

Exigiu ainda adequasse o ECAD o seu Estatuto àquelas disposições e providenciasse o seu Regimento interno.

As associações estrangeiras que administrarem os direitos de competência daquele Escritório, deverão outorgar poderes a uma das associações vinculadas ao ECAD.

Cuidando o art. $6^{\circ}$ das Associações $e$ dos Titulares de Direito esmiuça que aquelas cuja natureza esteja compreendida na finalidade do ECAD, poderão a este se associar, desde que atendam aos requisitos que especifica.

$\mathrm{O}$ art. $7^{\circ}$ aponta serem órgãos do ECAD: a. Assembléia Geral; b. Comissão Diretora; c. Comissão Fiscal, tratados respectivamente.

Indica a competência da Coordenadoria Geral; prevê a criação, pela Comissão Diretora, de departamentos especializados; regula a fiscalização e escrituração e, finalmente, nas Disposições Gerais $e$ Transitórias regulamenta o fundo social, a eventual dissolução do ECAD.

\section{Estatutos e Regimento}

Elaborados com base na resolução no CNDA n 19, de 20/05/1980, por todas as associações de titulares de direitos autorais autorizadas a funcionar no País (menos a SBAT - Sociedade Brasileira de Autores Teatrais, que se recusou a participar), os estatutos do ECAD, aprovaos pela Resolução $\mathrm{n}^{\circ}$ 20, do CNDA, são constituídos por 63 artigos, distribuídos em 10 Capítulos, definindo:

"Art. 1" - O Escritório Central de Arrecadação e Distribuição, que adota na sua denominação a sigla ECAD, é uma associação civil sem finalidade lucrativa, constituída e organizada com prazo de duração indeterminado, por Associações de Titulares de Direitos do Autor e dos que lhe são conexos, na forma do que preceitua o art. 115 da Lei $n^{\circ} 5.988$, de $14 / 12 / 1972 "$.

Tais estatutos, antecedem três outros documentos:

a. O regimento interno do ECAD; 
Aprovado pelo seu Conselho Diretor em reuniões extraordinárias realizadas nos dias 07 e 08/11/1980, é constituido por 50 artigos, distribuídos em sete Capítulos, que versam, respectivamente:

I. Natureza e Finalidade;

II. Órgãos do ECAD (a. Assembléia Geral; b. Comissão Diretora; c. Comissão Fiscal);

III. Da Assembléia Geral;

IV. Da Comissão Diretora;

V Da Comissão Fiscal;

VI. Da Coordenadoria Geral;

VII. Disposições Gerais.

b. O regulamento de distribuição de direitos de autor e conexos, e

c. A fixação dos critérios, sistemas e valores para a arrecadação desses direitos.

Todos esses documentos, que complementam o desenho da nova estrutura do Escritório, aprovados pela CNDA, facilitaram os trabalhos das eleições do novo quadro de dirigentes que se realizou no dia 14/10/1981, dentro da nova ordem estabelecida, tendo sido eleito Presidente o Sr. Adelino Moreira, da SBACEIM.

Anota JOSÉ CARLOS COSTA NETTO terem sido mudanças fundamentais, entre outras:

a. A centralização da arrecadação: o que antes funcionava somente para a música vai funcionar para áreas não atendidas de titulares de direitos de autor e conexos.

b. Foi criada a figura da "Assembléia Geral" órgão supremo do $\mathrm{ECAD}$, na orientação de suas atividades. Será realizada, ordinariamente, uma vez por ano e extraordinariamente, quantas for necessário, e integrada por todas as associações que compuserem o Escritório;

c. Foram estabelecidas sete coordenadorias (executivas): uma geral, e outras: administrativa, financeira, de arrecadação, de distribuição, de serviços jurídicos e de cadastro;

d. A figura dos "departamentos" especializados para a administração dos direitos autorais, segundo as suas respectivas naturezas e peculiaridades, garantirá tratamento diferenciado a cada modalidade de direito de autor ou conexo, em consonância com a orientação dos respectivos titulares, representados por sua associação; 


\section{Críticas e sua refutação}

A firme determinação da implantação de um sistema tão inovador dos vícios de arrecadação, a exigência da indicação dos repertórios de cada entidade, uma sadia e drástica redução das despesas de "administração", a implantação de um desusado rigor de fiscalização, haviam fatalmente de desagradar centenas de pessoas que até então usufruíam uma liberdade de ação sem limitação e sem controle.

Dentre as críticas que sofreu a Resolução $\mathrm{n}^{\circ}$ 19, três são as principais:

A primeira é a de que o art. 73 da Lei $n^{\circ} 5.988$ se destinaria exclusivamente às composições musicais e litero-musicais, não tendo pois o novo órgão competência para imiscuir-se com relação às obras teatrais.

$\mathrm{Na}$ verdade, a princípio, na gestão anterior do CNDA, o ECAD preocupou-se apenas com as execuções musicais, pressionado, talvez, pelas reivindicações dos compositores e dos artistas, reclamando muito os primeiros contra as sociedades arrecadadoras.

Com a aprovação da Resolução $n^{\circ} 19$, que procurou atender a todos os demais setores da produção intelectual, a direção da Sociedade Brasileira de Autores Teatrais (SBAT), sentiu-se atingida na sua prerrogativa de arrecadar direitos de seus associados, alegando que sua ação teria sido "usurpada", e não aceitando que ao ECAD fosse reconhecida a possibilidade de autorizar a utilização da obra.

A simples transcrição do aludido dispositivo mostra a total falta de base do argumento na parte em que dispõe que sem autorização do autor, não poderão ser transmitidos pelo rádio, serviço de alto-falantes, televisão ou outro meio análogo, representados ou executados em espetóculos públicos e audições públicas, que visem a lucro direto ou indireto, drama, tragédia, comédia, composição musical com letra ou sem ela, ou obra de caráter assemelhado.

É claro que o inteiro contexto abrange os próprios "espetáculos públicos e audições públicas" a que se dirige.

Ou será que uma peça teatral não é representada ou executada em espetáculos públicos, visando lucro, nem é drama, tragédia ou comédia ou ainda obra de caráter assemelhado.

Reiteradamente tem manifestado o Presidente do CNDA, JOSÉ CARLOS COSTA NETTO, que longe de ter a sociedade arrecadadora seu trabalho limitado, contido e restrito, a idéia é acrescentar esse trabalho a uma estrutura maior, mais segura e mais abrangente.

A centralização não muda nada, a não ser o fato de existir uma centralização, mantidos totalmente os critérios de distribuição de cada sociedade. 
Mas a verdade é que, longe de prejudicar os autores teatrais, a filiação da SBAT ao ECAD (que de resto, é uma imposição da lei) só os beneficiaria, reconhecido não estar ela estruturada para cobrar os direitos do cenógrafo e do coreógrafo (que não deixam de ser autores ligados à arte teatral).

$\mathrm{Na}$ televisão; por exemplo. Se eles são autores e a SBAT, em termos de representação, é a sociedade competente, a quem caberia esta arrecadação e distribuição? De acordo com a Resolução $\mathrm{n}^{\circ} 19$ ao ECAD, por serem direitos conexos.

$A$ segunda objeção é contrária às expressões contidas no art. $2^{\circ}$ da Resolução $\mathbf{n}^{\circ}$ 19, que, tomadas ao pé da letra, dariam a entender que

“ cabe ao ECAD autorizar a utilização de obras intelectuais"

Não é essa, evidentemente, a intenção, ainda que as expressões não sejam felizes.

A autorização considerada não é a do ECAD, por si, mas como representante do próprio titular do direito, ou da associação à qual ele pertença, que por intermédio do ECAD, concederão ou não permissão para a utilização da obra.

Como as associações comandam o ECAD, compartilham em termos decisórios. Como o ECAD é uma associação de associações, que por sua vez é composta pelos titulares de direito autoral, a permissão no final vai caber ao próprio autor, intérprete ou executante.

Aos receios de que, integrando-se ao $\mathrm{ECAD}$, a SBAT ficaria sob fiscalização do Governo, o presidente do Conselho lembra que, desde a criação do CNDA - há quatro anos - a associação já está sob o controle e a fiscalização do Governo. "Há quatro anos a SBAT envia seus balancetes, como também o próprio ECAD, para aprovação do Conselho"

O fato de a SBAT ficar fora da lei prejudica as demais oito sociedades que fazem questão de integrar o sistema, e só trará confusões, uma vez que o ECAD arrecadará os direitos conexos do teatro atores, música, etc. - cujas sociedades o integram.

A terceira objeção é a de que pelo ECAD estaria sendo promovida a estatização das associações de cobrança de direitos autorais e conexos, quando, na verdade, prestigiando-o, outra coisa não faz o CNDA senão aplicar a legislação específica em pleno vigor.

O ECAD não passa de uma sociedade civil: seu âmbito não é governamental; o Governo outra interferência não teve senão determinar a sua constituição. Limita-se, como as demais associações de direitos autorais, pelas quais é constituído, à arrecadação que, quando não é relativa aos filiados diretos, repassa às demais associações, facilitando-lhes o serviço e diminuindo a responsabilidade. 
Como as demais, está subordinado ao Conselho Nacional de Direito Autoral que fixa as normas para unificação dos preços e sistemas de cobrança e distribuição de direitos autorais.

E o suficiente para demonstrar que o ECAD não pertence ao CNDA, e, portanto, não é órgão do Governo: centraliza apenas a arrecadação e distribuição dos direitos de execução pública de obras musicais, a serviço das próprias associações.

\section{O ECAD mudou no panorama da cobrança do direito de autor no Brasil}

Pinta o Desembargador MILTON SEBASTLÃO BARBOSA, em cores vivas a realidade que a Lei $\mathrm{n}^{\circ} 5.988$ veio modificar.

A inexistência de um órgão único arrecadador de proventos decorrentes da execução e representação de obras autorais sempre gerava:

a) proliferação desordenada e exagerada de órgãos cobradores dos usuários;

b) impossibilidade total do produto da arrecadação ser substancialmente encaminhado ao titular do direito, à vista do custo elevadíssimo dessa cobrança;

c) os agentes dessas sociedades (empregados ou não), sem obrigação de recolher, mediante guias próprias, incontinenti, à rede bancária o produto arrecadado, retinham o dinheiro, prestando, ou não, contas em largos periodos;

d) profunda desorganização, recalcitrante má vontade de pagar, maus cobradores gerando desconfiança, ausência de órgão fiscalizador.

Em 1976 o SDDA arrecadou Cr\$ $96.419 .635,19$ e a SICAM $\mathrm{Cr} \$ 49.624 .645,48$ perfazendo um total de Cr\$ 146.044.028,59.

Para aquilatar dos resultados proporcionados, pelo ECAD basta verificar como foram crescendo após a sua instalação:

$\begin{array}{ll}1977 \ldots \ldots & \operatorname{Cr} \$ 213.170 .814,42 \\ 1978 \ldots & \operatorname{Cr} \$ 375.228 .380,92 \\ 1979 \ldots \ldots & \operatorname{Cr} \$ 503.991 .828,45 \\ 1980 \text { (Até junho) } . \quad \operatorname{Cr} \$ 402.872 .525,69=\operatorname{Cr} \$ 1.495 .263 .549,48\end{array}$

O numero de titulares de direitos por ele beneficiados soma atualmente 13.620 (autores, editores, intérpretes e produtores) número com base na distribuição do $1^{\circ}$ trimestre de 1980.

Mas o trabalho do ECAD não se dirige apenas em aperfeiçoar a cobrança nos setores tradicionais. Dirige-se, também, com uma auto- 
ridade muito maior da que teriam as sociedades arrecadadoras por iniciativa própria, a setores que, praticamente, muito pouco contribuem no Brasil para as estatísticas finais, ao contrário do que ocorre em outros países: rádio, televisão, cinema.

Para tanto procura aperfeiçoar o seu sistema de controle.

A "Informa Som" - empresa que presta ao ECAD serviços de escuta de música em rádio e televisão — ampliou até fins de 1980 seu raio de ação para doze capitais. Além de São Paulo, Rio, Porto Alegre, Brasília, Recife, Salvador e Belém, cidades em que já atuava, também esteve presente em Curitiba, Belo Horizonte, Goiânia, Fortaleza e Manaus.

Depois de captadas músicas, por meio de gravadores, elas são codificadas e fitas magnéticas de computador são enviadas com todas as informações ao Serviço de Processamento de Dados do Ministério da Fazenda - Serpro. Lá, as fitas entram em computadores que checam os cadastros para identificar os compositores e já emite o contracheque, que será enviado às sociedades arrecadadoras, que por sua vez o entrega ao detentor dos direitos autorais. Atualmente os dados são remetidos às associações mensalmente.

Resolução $\mathrm{n}^{\circ} 8$ do CNDA de 22/12/1976 fixou as percentagens de dedução da arrecadação de direitos autorais.

Para a manutenção do ECAD, os descontos foram no primeiro trimestre de 1977 , de $30 \%$, no segundo, de $25 \%$ e no terceiro de $20 \%$, e, a partir de 1\% de outubro, de $15 \%$.

Para a manutenção das associações, os descontos foram de 5\% no primeiro semestre de 1977 e de $3 \%$ a partir de 01/07/1977, devendo ser recolhido ao fundo de direito autoral o percentual que seria destinado às associações que não foram autorizadas a funcionar.

Foi um passo duro, mas decisivo para a moralização do direito de autor, sabido como é que nada menos de $50 \%$ e até $60 \%$ da cobrança arrecadada eram dispendidos pelas associações de direitos autorais, de resto sempre em luta com a deficiência de pessoal e a grande extensão territorial a ser fiscalizada.

Mais uma resolução foi baixada fixando normas para a unificação dos preços e sistema de cobrança e distribuição dos direitos autorais, inclusive relativos à execução, pública por radiodifusão e exibição cinematográfica.

\section{As denúncias e a "intervenção"}

Os presidentes das Associações dos Atores e do Músicos, Arranjadores e Regentes, Jorge Ramos e Maurício Tapajós, solicitaram ao Conselho Nacional de Direito Autoral - CNDA - uma intervenção 
no ECAD para apurar atos de corrupção cometidos pelos seus dirigentes.

Em nota divulgada em Brasília no dia 06/01/1980, pediram uma ação enérgica do CNDA "no sentido de garantir a moralização e o fortalecimento dos mecanismos de defesa dos direitos de autores, compositores, intérpretes e músicos, hoje lesados, mais por negocistas que por representantes".

Entre as irregularidades, aponta: "Os resultados concretos da gravação de músicas executadas em emissoras de rádio e televisão são alterados nas listagens do ECAD: a presença de interessados na arrecadação de direitos autorais em setores de distribuição e fiscalização do ECAD vicia os resultados na partilha desses direitos; o ECAD distribui valores para EDITORES MIUSICAIS em nome de autores supostamente cessionários, uma vez que essas cessões não são documentadas e nem comprovadas; o ECAD distribui valores provenientes da execução de músicas estrangeiras para sociedades que não identificam essas músicas e não comprovam a sua representação".

Por nove votos contra um, o CNDA decidiu, aos 07/01/1980 realizar uma auditoria rigorosa no ECAD - Escritório Central de Arrecadação e Distribuição - para apurar as denúncias de irregularidades.

Pela Portaria $\mathrm{n}^{\circ}$ 6, de 10/02/1981 foi nomeado Interventor do ECAD o Dr. Luiz Roberto Fontoura de Carvalho, tendo sido sua permanência prorrogada por mais 30 dias, pela Portaria $n^{\circ} 8$, de 10-03-1981, do Presidente do CNDA (DO, I, 17-03-1981).

Noticiava a Folha de S. Paulo de 12-08-1981, que a autoria, realizada sobre as atividades do ECAD entre janeiro de 1978 e janeiro de 1981 pela empresa de São Paulo, Audimar, revelou, apenas no escritório central de Brasilia, desvio de dinheiro em benefício pessoal, adulteração de documentos, aplicações financeiras irregulares, adiantamentos de salários sem reposição posterior, descontrole em pagamentos de diárias de viagens e de agentesi e até a compra de uma saladeira de quase 26 mil cruzeiros.

No livro de contabilidade do escritório havia duas rubricas nunca vistas pelos auditores - "Futuros enganos" e "Não identificados" nas quais eram lançados os valores recebidos em nome de autores e sócios não identificados.

O relatório dos auditores está dividido em dez itens, examinando as aplicações financeiras, a conta "Arrecadação" na Caixa Econômica Federal, os recebimentos e adiantamentos, os deveres, os pagamentos $\mathrm{e}$ as indenizações a agentes do ECAD.

No item "Aplicações financeiras" ficou provado que as operações eram realizadas por longos prazos, "infringindo frontalmente o objetivo 
primordial do ECAD", cuja finalidade é arrecadar e distribuir direitos, sem prejuízos aos autores e associados, praticamente num único banco, o BESC (Banco do Estado de Santa Catarina) e uma delas, no valor de 16 milhões e 230 mil cruzeiros, foi realizada pelo prazo de 450 dias. O ECAD tinha ainda mais de 330 milhões presos ao BESC a título de aplicações que só serão liberadas ao longo dos próximos seis meses.

A conclusão da auditoria informa ainda que o ECAD, no período auditado, revelou absoluta ausência de planejamento estratégico e de controles internos operacionais e financeiros, além da adoção de uma política de recursos humanos voltada para o empreguismo e paternalismo.

\section{Auditoria nas Associações}

Tendo conhecimento de que graves irregularidades ocorriam também nas entidades de direitos autorais, o Presidente do ECAD, por Portaria de 17-02-1981, constituiu comissão para proceder a uma auditoria rígida em todas as sociedades de titulares de direitos autorais em funcionamento no País para uma apuração real das condições de funcionamento dessas entidades, entre as quais estão a AMAR, ANACIM, ASA, ASSIM, SABEM, SADEIMBRA, SBAT, SICAM E SOCIMPRO, cujo prazo também foi prorrogado por 30 dias pela Portaria $n^{\circ}$ 9, de 13-03-1981, publicada no mesmo órgão de 17 do mês citado.

Relatava o Presidente do CNDA, aos 16-09-1981, que a maioria das Sociedades de Titulares de Direitos Autorais que antes da Intervenção controlavam o ECAD (com exceção da AMAR e da ASA), não esconderam o desapontamento com as medidas reorganizativas e desde o começo procuraram repassar informações distorcidas aos autores sobre o produtivo trabalho realizado pela equipe de técnicos que assessoram a Intervenção, em sua fase transitória que estava atualmente ainda em andamento.

A situação se agravou quando a 11-08-1981, o Plenário do CNDA, em continuidade aos trabalhos da Intervenção, determinou fosse instalada fase transitória de administração no ECAD.

Essa fase, que deveria terminar em dezembro desse ano, com as eleições das sociedades "arrecadadoras" que iriam dirigir autonomamente o Escritório, ocasionou uma radicalização entre a posição reorganizativa do Supervisor Geral do ECAD e a das referidas Sociedades.

O Supervisor Geral em obediência a Resolução $n^{\circ}$ 2.181, de 02-12-1980, do CNDA, visava a centralização das atividades operacionais e de controle do ECAD em Brasília, visando tornar as Sucursais (SP, RJ, RS, PR, PE, AM, BA, CE) órgãos com objetivos definidos, no sentido único de atender os autores filiados ou não ao ECAD e bem como promover a Arrecadação, a Fiscalização e a Cobrança dos Direitos Autorais junto aos usuários, cabendo à matriz, Brasília, os controles 
operacionais e burocráticos, e às Sucursais as atividades de Agências Arrecadadoras e de Atendimento personalizado aos autores e sociedades.

Essa radicalização foi causada devido à não aceitação por parte das referidas sociedades das medidas reorganizativas impostas ao Escritório. O problema se agravou quando as Sociedades repudiaram a Tabela de Cobrança de Direitos Autorais que os autores por unânimidade haviam aprovado, em relação às emissoras de Rádio e Televisão.

Isso foi concretizado com um acordo em que 08 (oito) Sociedades (SBACEM, SADEMBRA, UBC, SICAM, SOCINPRO, ASSIM, ANACIM e SABEM) firmaram com a ABERT - Associação Brasileira de Emissoras de Rádio e Televisão.

Paralelamente, alguns compositores desavisados e desinformados pela campanha de Imprensa que chegou até a ser violenta, não se poupando em manchar nomes e dignidades de pessoas de conduta moral intocável, ocuparam a Sucursal do ECAD no Rio de Janeiro, sem qualquer ato de força de parte tanto do ECAD como do CNDA, na esperança dos resultados de um bom diálogo, situação de que se aproveitaram as sociedades que queriam a todo custo voltar de imediato às rédeas do ECAD.

Esse estado de coisas, desembocou na sessão plenária do referido dia 16 do CNDA, que por 06 (seis) votos a 0 pôs fim à fase de transição administrativa do ECAD.

Houve, imediatamente, uma invasão na sede do ECAD em Brasilia, e já se acionava o mesmo procedimento na Sucursal do ECAD em São Paulo.

A condução administrativa do ECAD a partir dessa data voltou às mãos das Sociedades Arrecadadoras.

O ex-ministro da Educação e Cultura, RUBEM LUDWIG, no entanto, pela Portaria $n^{\circ} 550$, de 01-10-1981, considerando que o término da intervenção e a posterior fase transitória da administração não deve acarretar solução de continuidade dos projetos e benefícios obtidos na administração do escritório, nem retrocesso na reorganização promovida em suas atividades de arrecadação e distribuição de direitos autorais, determinou instituísse o CNDA uma fiscalização permanente no Escritório Central de Arrecadação e Distribuição ECAD - , para dar continuidade a auditorias e inquéritos administrativos que tenham o objeto de sanear administrativamente esse órgão. Estas e outras determinações constam de portaria assinada pelo ex-ministro Rubem Ludwig.

Além da continuidade de auditorias e inquéritos, de projetos e demais benefícios administrativos de arrecadação e distribuição, obtidos no período de Intervenção e na fase transitória do escritório, 
determina que o ECAD apresente relatórios periódicos de atividades, submeta-se a uma fiscalização permanente e apresente previamente ao CNDA justificativas para ajustes, alterações de contratos e patrimoniais.

Em obediência a essas determinações, baixou o Presidente do CNDA, no dia seguinte, duas portarias: a de $n^{\circ} 30$, estabelecendo normas complementares de funcionamento e fiscalização do ECAD, e a de $n^{\circ} 31$, nomeando o Dr. Élcio de Oliveira Vieira responsável para serviços de fiscalização permanente do ECAD.

A providência era tanto mais necessária porquanto, segundo noticiava a imprensa de 01-10-1981, as associações que retomaram a direção do escritório já iniciaram a revogação de providências adotadas pela intervenção, entre as quais está o processo de arrecadação e distribuição, através de computador, para retomar os cálculos manuais.

Esperamos, por essa forma, fique definitivamente superada uma fase de incompreensão e injustiça, em que, em nome de princípios democráticos e invocações de textos legais conclados com fins demagógicos, mas não praticados, possam as associações prestar efetivamente aqueles serviços de utilidade pública a que estão destinadas, e não servir interesses escusos e pessoas inescrupulosas que contam com a simpatia, para não dizer, conivência dos que da situação retiram proveitos mediatos ou imediatos.

\section{Bibliografia Aproveitada}

CHAves, Antônio - Nova Lei Brasileira de Direito de Autor, S. Paulo, Ed. Rev. dos Tribunais, 1975, págs. 69-71.

FRóES, Carlos Henrique de C. - Direito de Arena, Tese apresentada no dia 19-08-1981, no X Congresso Mundial de Direito, Hilton Hotel, S. Paulo, 6 págs. mimeografadas. 